\title{
LAS IDEAS POLÍTICAS \\ DE SIMONE WEIL \\ SOBRE LA BARBARIE \\ Y LA CRISIS DE LA \\ CULTURA OCCIDENTAL
}

Gabriela Hernández*

\section{Introducción}

\section{“Estamos en la barbarie”. No es la}

primera vez que la humanidad se ha hundido en una negra noche del espíritu. La historia había parecido ser de algún modo ese eterno ciclo en el que las culturas florecen, alcanzan un auge y luego se sumen en una decadencia hasta que desaparecen, dejando apenas unos cuantos vestigios; pero la caída de una cultura anunciaba la aparición de un nuevo impulso de vida. A cada expansión sucedía un declive, pero allí mismo donde sucumbía una cultura, o en otra región del planeta, surgía una línea más del desarrollo de la civilización que se erigía con nuevos bríos vitales. Por el contrario, la decadencia de una cultura nunca había significado un declive generalizado de la civilización en todos sus órdenes; las crisis estaban localizadas y el ocaso de una cultura era correlativo del auge de otra. En diversos modos, la capacidad transformadora que el hombre posee sobre su propio ser permanecía inafectada. En todas las variaciones históricas, en la serie de cambios, decadencias y florecimientos habría que ver que el poder de diversificar la

\footnotetext{
* Departamento Académico de Estudios Generales, ITAM.
} 


\section{GABRIELA HERNÁNDEZ}

vida, el poder de ser y transformarse a sí mismo permanence en el hombre como un principio inalterado. El hombre es proteico, adquiere diversos modos de ser, construye distintas ideas del hombre, en las que se expresa, por un lado la forma propia que adquiere y la autoconciencia de esa creación, lo cual conlleva una serie de atributos ideales-posibilidades que se proyectan como valores que orientan la realidad del hombre.

Sin embargo, lo que sucede en nuestros tiempos es algo nunca visto. La era moderna ha significado el desarrollo expansivo de un conjunto de saberes 'científicos' y del poder tecnológico que se ha erigido sobre la base de ese saber, por encima de los demás valores de la vida. La expansión sin precedentes del poder tecno-científico es correlativa del hundimiento de los valores morales, religiosos y aun estéticos. El hombre moderno ha valorado más el conocimiento y la manipulación de ese mundo objetivo de pura materialidad, que el mundo de la vida que lo presupone y lo fundamenta, que el mundo espiritual de la experiencia consciente, en sus muy diversos sentidos. Percibimos en el espíritu de nuestro tiempo una crisis generalizada en la que no es una cultura la que se encuentra en decadencia, sino toda cultura; pues esa decadencia no se equilibra con algún florecimiento. Pero ello no significa que nuestros tiempos carezcan de fuerza vital. De hecho, nuestra crisis no es de escasez y austeridad, sino de sobreabundancia, de exceso, de hybris en más de un sentido, el hombre está sobrado de vitalidad, pero ha perdido el dominio y el conocimiento de sí mismo. Nuestros medios son poderosísimos, podemos hacerlo todo, no obstante, no sabemos qué hacer, ni cómo ni para qué. Tal parece que lo que ha entrado en crisis es la capacidad misma del hombre para formar y transformar su propio ser, para construir una idea del hombre auténtica y diferente de las anteriores.

El hombre decae en su poder-ser, en su ser proteico; su vida se ha uniformado, los valores que antes regían su existencia se han disuelto en la uniformidad de la vida que sólo aprecia la objetividad de lo conocido y manipulado por el poder tecno-científico. Esta transformación se produce en el ser mismo del hombre. ¿Por qué la apertura hacia un 
conocimiento que por primera vez se alza con objetividad y rigor indiscutibles es paralelo del hundimiento de los demás valores de la vida? La crisis de la cultura que apenas puede disimularse hoy en día, ha sido objeto de innumerables análisis. La fragmentación y especialización del conocimiento, así como la renuncia a las explicaciones totalizadoras parecen ser algunos de sus síntomas más conocidos. El conocimiento se convierte en un saber tecnificado sobre las cosas, sobre las objetividades, sobre lo 'real'. Surge entonces la presunción de que los diversos conocimientos especializados y tecnificados constituyen el único saber válido y aun posible, la única forma para que sea eficaz. La paradoja nunca antes vista es el síndrome de la crisis de nuestros tiempos: la explosión del desarrollo tecno-científico y el declive del hombre en lo que concierne al saber de su propia existencia, de su propio ser histórico y no sólo de las cosas del mundo. Es la nueva barbarie que no parece poder ser superada por una nueva oleada de vitalidad que mueva en conjunto las fuerzas vitales y los valores humanos.

Ahora bien, la barbarie no es el comienzo de la civilización, ni puede ser el inicio de su auge. Ella siempre llega después, con respecto a un estado de cultura anterior que ha perdido el fundamento de su existencia. La barbarie es empobrecimiento y degeneración de las modalidades de la vida. Es la merma de las potencialidades del ser humano. La barbarie es la ruina de un estado de aculturación; no un estado rudimentario, primitivo. Todo comienzo de la civilización representa una eclosión de vitalidad, mientras que la barbarie representa su caída, su recogimiento.

Pero ahora la barbarie no es la decadencia de una o unas cuantas culturas, es la decadencia de todas, del ser del hombre. La barbarie era correlativa con la aculturación; ahora es forma predominante, que quiere decir el predominio de lo deformado, de lo informe.

El estado de cultura en el hombre representa una fuerza creadora capaz de transformar la vida desde sí misma. Cultura designa autotransformación de la vida, pero también autoconciencia, experiencia de sí misma, expansión, desarrollo, movimiento por el que la vida no cesa de modificarse para alcanzar formas conscientes más 
GABRIELA HERNÁNDEZ

plenas y desarrolladas. Pero la transformación de la vida no es ciega, se apoya en un saber preciso que precede a todo saber teórico o científico. El saber de la vida, un saber sin objeto, un saber que implica el experimentarse a sí misma, que se funda en las intuiciones primarias de lo real, el factum o, si se quiere, el apriori de una autoconciencia plena de sentido, que se dirige al mundo y que lo impregna con su presencia, es el fundamento de todo saber de la conciencia y de toda ciencia posible. Antes que el saber ideal y objetivo existe un saber esencial, una intuición fundamental que proviene de la irradiación de la conciencia que se despliega hacia todo el mundo circundante. Pero si este saber tiende a la formación, al movimiento, ¿por qué es susceptible de detenerse e invertirse? Si es un saber fundamental, ¿cómo puede ser velado o sustituido por un saber secundario, objetivo e ideal que reduce el mundo percibido a un conjunto de fórmulas ideales que la conciencia misma elabora? Lo que perturba no es que la barbarie exista sino que sea siempre una posibilidad inherente a toda civilización. Tal parece que es propia de la existencia humana la posibilidad de restringir sus capacidades vitales, de reducir su espectro de experiencia y de mutilar los vínculos profundos con la realidad del mundo

en torno. Comprender la decadencia propia de nuestra época es reconocer la posibilidad de un declive en la vida, de un decaimiento de la vitalidad que ahora afecta a toda cultura. ¿Qué factores intervienen en esta crisis radical y universal? ¿Por qué lo que parece ser el máximo logro de la civilización: el dominio técnico de la naturaleza, se produce dentro de una crisis generalizada de los valores?

\section{Las ideas políticas de Simone Weil}

\section{Esbozo biográfico}

Simone Weil nació en 1909 en París; hija de una familia judía de clase media -su padre era médico- hizo sus estudios superiores en la Escuela Normal Superior (1925-6), en donde obtuvo la licenciatura en filosofía, 
y posteriormente comenzó a enseñar filosofía en los liceos de Le Puy, Auxerre y Roanne. Al mismo tiempo que iniciaba su carrera docente florecían sus inquietudes políticas militando en una confederación de sindicatos de filiación comunista. En 1934 pide permiso para desarrollar estudios personales, redacta sus Reflexiones sobre las causas de la libertad y de la opresión social, un texto de aguda crítica al marxismo de principios del siglo, un tanto de inspiración anarquista. Abandona su carrera académica para irse a trabajar durante un año (1934) como obrera en la Alsthom y luego en la Renault. En 1936 se enlistó en una brigada internacional para defender a la República Española, aunque no quiso utilizar jamás las armas y fungió más bien como organizadora; regresó a Francia dos meses después al sufrir en la guerra española una quemadura accidental en una pierna. Al siguiente año regresó a impartir clases y comenzó a escribir La condición obrera.

Una profunda crisis religiosa, después de realizar dos viajes a Italia en 1938, la llevó al cristianismo, y posteriormente a estudiar con gran interés los textos de distintas religiones, como la hindú o la tradición órfica y pitagórica de la antigua Grecia (leía y traducía del griego). Comienza su interés por los temas de la revelación, la gracia y la mística cristiana (fruto de estas reflexiones son las notas publicadas en $L a$ gravedad y la gracia). A partir de entonces traba amistad con religiosos como el padre Perrin, a quienes cuestiona constantemente para conocer el contenido exacto de la fe cristiana. Sus cuestionamientos a la Iglesia católica quedaron plasmados en Carta a un religioso, dirigida al padre Perrin. Como otros pensadores judíos, Simone Weil no se convirtió al cristianismo mientras su familia fue perseguida por los nazis. En 1942, en plena ocupación alemana y debido a los problemas por su origen judío, se embarca para Nueva York con su familia. Ahí la contratan para el servicio interior de relaciones con la resistencia francesa y emprende el viaje hacia Londres. De esta época es el escrito El arraigo, preludio a una declaración de los deberes hacia el ser humano. En diciembre del mismo año comienza a trabajar para la resistencia francesa. Enferma de tuberculosis y antes de morir, en agosto de 1943, pide a su amiga Simone Deitz la bautice en el hospital. 


\section{GABRIELA HERNÁNDEZ}

Los textos de Simone Weil están expresados con frecuencia en breves notas sobre diversos temas, algunos más desarrollados que otros, pero todos son más bien esbozos de libros; no publicó más que algunos artículos en diversas revistas. Todos sus libros fueron publicados póstumamente: La fuente griega, El arraigo, La gravedad y la gracia, En espera de Dios, Opresión y libertad, La condición obrera, Carta a un religioso, son los más representativos. Para nuestro tema caben destacar: La condición obrera, que contiene su diario de fábrica, en el que narra su experiencia de la 'gravedad' de la condición trabajadora; y Opresión y libertad, que contiene uno de sus textos más acabados: "Reflexiones sobre las causas de la libertad y de la opresión social”, en donde expone una crítica al marxismo, así como los elementos de una teoría política, en torno al concepto de opresión.

Simone Weil quiso vivir la experiencia de ser obrera, es decir, la experiencia de la opresión y la fatiga, renunciando a su labor académica en los liceos. Se podría objetar que por el hecho mismo de ser una maestra 'burguesa' no podría experimentar auténticamente la condición obrera. No obstante, su diario de fábrica y sus reflexiones sobre el trabajo demuestran lo contrario. A Simone Weil le preocupaba el dolor individual y colectivo, la enajenación de la persona, la imposibilidad de una vida reflexiva en medio del trabajo más arduo y fatigante. Simone Weil se percataba de que el dolor puede destrozar a los hombres, anulando su espiritualidad y su capacidad de pensamiento. Esta situación vivida en carne propia la lleva a reflexionar sobre las posibilidades de la liberación del trabajo obligatorio y de la explotación.

El gran dolor del trabajo manual es que se está obligado a hacer un esfuerzo en horas tan largas, simplemente para existir. El esclavo es aquel que no se propone ningún bien como objeto de sus fatigas sino la simple existencia. [...]

Trabajo manual. El tiempo que penetra en el cuerpo. Por el trabajo el hombre se hace materia, como Cristo por la Eucaristía. El trabajo es como una muerte. Es necesario pasar por la muerte. Es necesario ser muerto, sufrir el peso del mundo. El 
universo pesando sobre los riñones de un ser humano. [...] El pensamiento está obligado a pasar de un instante a otro sin aferrarse al pasado ni al futuro. Es obedecer. ${ }^{1}$

Para Simone Weil, la liberación del obrero es un rescate de su espiritualidad por la vía religiosa, pero no como camino de nueva enajenación, sino como una guía para aceptar el sufrimiento y buscar la alegría y el goce de vivir, sin renunciar a una mejor vida libre de opresión.

Los trabajadores tienen más necesidad de poesía que de pan. Necesidad de que su vida sea poesía. Necesidad de una luz de eternidad. Únicamente la religión puede ser la fuente de esta poesía. No es la religión, sino la revolución el opio del pueblo. La privación de esta poesía explica todas las formas de desmoralización. $^{2}$

\section{La Ilíada o el poema de la fuerza}

El artículo “La Ilíada o el poema de la fuerza” fue escrito en 1939-40 y estaba a punto de aparecer en la Nouvelle Revue Française cuando estalló la ofensiva alemana sobre Francia. No pudo publicarse en el París ocupado. Apareció en Marsella, en los Cahiers du Sud (1940-1) con el seudónimo de 'Emile Novis'.

Simone Weil poseía un amplio conocimiento de la cultura griega: los pitagóricos, los órficos, las tradiciones herméticas, Platón (leído desde las tradiciones órficas y pitagóricas), los presocráticos, Homero, etc. De los textos que reúne La fuente griega, el análisis sobre $L a$ Ilíada y el ensayo sobre el tema de Dios en Platón, son los más reveladores de su pensamiento, en el que se mezclan teorías de 'pura' especulación con intuiciones de carácter más bien religioso. En estos textos

${ }^{1}$ Simone Weil, La gravedad y la gracia, p. 248-9.

${ }^{2}$ Ibid. 


\section{GABRIELA HERNÁNDEZ}

se muestra la intención de Simone Weil por hallar una relación de continuidad entre las tradiciones más profundas del espíritu helénico y el cristianismo originario, lo cual es un intento de buscar la raíz de una revelación primitiva, esencial, que subyace en el espíritu de Occidente. Simone Weil no descartaba tampoco los vínculos de las grandes tradiciones helénica y cristiana con la del hinduismo, que también estudió esmeradamente.

El análisis de La Ilíada que realiza Simone Weil no es un estudio filológico ni literario, es un análisis ontológico de la 'fuerza'; de aquello que hace que cualquier hombre esté sometido a una cosa, y de aquello que convierte en una cosa a cualquier hombre. Se trata de un ensayo de ontología del poder, de análisis de ese impulso que se cierne sobre los hombres y que los somete a sus designios, tanto a los opresores como a los oprimidos, tanto a los vencedores como a los vencidos. El alma del hombre ha sido modificada constantemente por sus relaciones con la fuerza, arrastrada y obnubilada por la 'fuerza' de la que cree disponer, sometiéndose a la presión que desata y padece.

Simone Weil tiene por objetivo profundizar en el tema del poder 'puro', del poder, o más bien de la ‘fuerza’ en sus formas más originarias de manifestación, sin mediaciones sociales, sin representación cultural. Simone Weil ve en el poema de La Ilíada una manifestación originaria de la fuerza, una pura expresión de la condición humana sometida al poder, un canto a la miseria del hombre.

Cuando se ejerce hasta el fin [la fuerza], hace del hombre una cosa en el sentido más literal, pues hace de él un cadáver. Había alguien y, un instante después, no hay nadie. Es un cuadro que La Ilíada no se cansa de presentar. ${ }^{3}$

La fuerza que mata es su manifestación más descarada. Mucho más terrible es la que no mata, es decir, 'la que no mata todavía' -dice Simone Weil. Es la fuerza que amenaza, que conmina y aproxima la

3 “La Ilíada o el poema de la fuerza” en La fuente griega, p. 11. 
muerte, es la que se mantiene suspendida en la conciencia del hombre, y que lo paraliza. Del poder de aniquilar a un hombre matándolo, que es poca cosa, se desprende otro poder extraordinario que consiste en convertir en una 'cosa' inerte a un hombre que todavía vive. La fuerza es una sentencia de muerte. Puede aniquilar de inmediato, pero puede también ser una lenta e insidiosa, poderosa e inexorable forma de matar al hombre en vida, sometiéndolo, enajenándolo. Es el poder del sometimiento, de la explotación, de la enajenación que media entre dos hombres, pero que de ninguna manera pertenece a uno de ellos.

Así pues, la 'fuerza' se expresa en la guerra, en el pólemos que gobierna las relaciones entre los hombres, en ese impulso que -como dice Heráclito- "es el padre de todas las cosas y el rey de todas, a unos los hace dioses, a otros los hace hombres, a unos los hace libres, a otros los hace esclavos”. Y es precisamente la 'fuerza' que se manifiesta en la guerra aquello que cosifica al hombre, aquello que convierte una contradicción en una realidad: el espíritu, el cuerpo vivo se hace cosa, inerte, impotente, inmovilizado; esto es lo que desgarra al espíritu, que es automovimiento, vida, expansión, y que sometido, aniquilado, inmovilizado, está desgarrado, herido de muerte sorda y lentamente. Por ello, La Ilíada, según escribe Simone Weil, es un canto de extraordinaria amargura por la miseria humana:

Tan implacablemente como la fuerza aplasta, así implacablemente embriaga a quien la posee o cree poseerla. Nadie la posee realmente. En La Ilíada los hombres no se dividen en vencidos, esclavos, suplicantes por un lado y en vencedores, amos por el otro; no se encuentra en ella un solo hombre que en algún momento no se vea obligado a inclinarse ante la fuerza. ${ }^{4}$

Simone Weil establece una ecuación perfecta entre la fuerza, la guerra y la muerte. Por la fuerza, la miseria humana se hace efectiva, nadie es fuerte ante la inminencia de la muerte, el hombre es igualado por la

${ }^{4}$ Ibid., p. 18. 


\section{GABRIELA HERNÁNDEZ}

fuerza. En La Ilíada todos los personajes quieren parecer fuertes y valerosos pero la 'fuerza' los muestra en su debilidad esencial. La hybris, la ira del guerrero se paga con el sometimiento a la fuerza, el poderoso es víctima de su propio poder, porque éste no le pertenece, es una cosa que está por encima de él y de todos; la fuerza somete a todos y se vuelve contra el que la invoca.

Hay que advertir que la relación entre la fuerza y la muerte no surge de una reflexión existencial sobre la inherente mortalidad y finitud del ser humano. La muerte que se cierne por vía de la fuerza y la guerra no es natural, no es la finitud esencial del ser humano, no es la imposición de la naturaleza sobre una de sus criaturas; es la aniquilación artificial, es el desgarramiento de la vida por una fuerza que no proviene de la naturaleza, proviene del hombre mismo, pero que él no controla, no dispone y no dirige. En La Ilíada incluso ni los dioses dirigen y disponen de la 'fuerza', ellos mismos también son sometidos a su poder. La fuerza y la guerra crean una conciencia distinta de la muerte y de la vida, muestran que la muerte está al acecho, la aproximan, la encarnan en la ira del guerrero. La muerte no es próxima por una reflexión existencial inocua, se vive y se percibe por medio de la fuerza y de la guerra.

Simone Weil advierte que en La Ilíada la guerra es un juego de balanza, un movimiento pendular que hace pasar la dicha de la victoria y la desgracia de la derrota de un lado al otro y viceversa. Simone Weil observa en esta peculiaridad del poema homérico una sanción de rigor 'geométrico' que castiga el abuso de la fuerza en quien sobrepasa los límites de su uso. Para Simone Weil esta 'balanza' de la fuerza constituye el alma de la epopeya; bajo el nombre de némesis es el resorte en las tragedias de Esquilo y en las doctrinas de los pitagóricos, es una idea que reaparece en Sócrates y en Platón como base para pensar la unidad entre el hombre y el cosmos. Esta noción -continúa Simone Weil- se hizo familiar en donde penetró el helenismo, está quizá relacionada con aquella idea del karma de los pueblos orientales. Pero Occidente ya la ha olvidado. Las ideas de límite, mesura y equilibrio (nociones esencialmente ‘ético-geométricas’) que deberían 
determinar la conducta de la vida sólo tienen, desde la edad moderna, un empleo servil y utilitario en la técnica. "No somos geómetras más que ante la materia; los griegos fueron primero geómetras en el aprendizaje de la virtud." 5

Pero el movimiento pendular de la guerra es un estado de enajenación, es el estado en el que la muerte siempre está próxima, amenazante. El hombre se acostumbra a vivir en guerra, se enajena en la proximidad de la muerte violenta, se somete a la fuerza, incluso la adora. El hombre llega a no creer que la guerra puede desaparecer, la considera un estado 'natural', incluso la proyecta hacia toda la naturaleza. La guerra cosifica, es monótona, el hombre se somete a la violencia enajenando su ser.

La guerra posee un poder de enajenación prodigioso. Por la guerra, el hombre vuelve a someterse a la implacable necesidad. La relación entre la muerte y el porvenir no es igual que en los demás hombres. Para los otros la muerte es un límite impuesto al porvenir, para los guerreros es el porvenir mismo. Que los hombres tengan por porvenir la muerte es algo contrario a la naturaleza; precisamente porque la muerte es un límite fijo, preestablecido, desde que se nace y se comienza a vivir el hombre proyecta fines de vida ganando terreno a la muerte. Pero desde que la guerra hace inminente la posibilidad de muerte en cada minuto, el pensamiento se vuelve incapaz de soportar los días sin con-vivir con la imagen de la muerte. El espíritu en guerra se hunde en una violencia y monotonía cotidianas, pues cada día de tensión en guerra, el alma se mutila un fin vital, una aspiración existencial. Así, la guerra diluye toda idea de fines, hasta los fines de la guerra y la intención misma de poner fin a la guerra.

Sin embargo, el alma sometida a la guerra clama por su liberación; pero la liberación misma se le aparece bajo una forma trágica, extrema, bajo la forma de destrucción. Un fin moderado, razonable, mostraría desnuda ante el pensamiento una desgracia tan violenta que ni siquiera puede soportarse como

${ }^{5}$ Ibid., p. 22. 
GABRIELA HERNÁNDEZ

recuerdo. El terror, el dolor, el agotamiento, las muertes [...], no puede creerse que todas esas cosas cesen de morder el alma si la embriaguez de la fuerza no las ahoga. ${ }^{6}$

Ésta es, pues, la naturaleza de la fuerza. El poder que posee para transformar a los hombres en cosas es doble y tiene dos sentidos; petrifica y aniquila, de diferente forma pero en similar intensidad, a los que la sufren y a los que la detentan.

Para Simone Weil, la tragedia es la verdadera continuación de la epopeya. La fuerza aparece siempre implacable para quien la sufre y para quien la ejerce. A través de La Ilíada se expresa el genio griego que muestra, por un lado, la búsqueda del orden, excluyendo todo otro bien, y por otro, la miseria humana, la miseria de un ser divino y humano al mismo tiempo. A lo largo de la historia del hombre la miseria humana ha sido puesta al desnudo en varias ocasiones. Pero lo que $L a$ Ilíada nos muestra es único: "no hay que creer nada al abrigo de la suerte, no admirar jamás la fuerza, no odiar a los enemigos ni despreciar a los desgraciados. Occidente mostró, después de los griegos, la miseria humana en el amor, mientras que los efectos de la fuerza en la guerra debían estar siempre envueltos de gloria. Occidente convirtió el relato original del genio épico en 'cantares de gesta’. Para Simone Weil, “El Evangelio es la última y maravillosa expresión del genio griego, así como La Ilíada es la primera.”7

Reflexiones sobre las causas de la libertad y de la opresión social.

La crítica política de Simone Weil se concentra en tres polos: La crítica a Marx, al socialismo real y a la idea de progreso. Estos temas aparecen en Reflexiones sobre las causas de la libertad y de la opresión social. Simone Weil critica la confianza de Marx en el progreso de las fuerzas productivas que, una vez liberadas, estarían al servicio de

${ }^{6}$ Ibid., p. 29.

${ }^{7}$ Ibid., p. 38. 
todos los hombres. Pero la emancipación no ha sido de los hombres, sino de las fuerzas productivas. Para Simone Weil, la sumisión del obrero no está dada sólo en un régimen determinado de propiedad sino en la producción industrial misma, que en cuanto aumenta su poder y acelera su desarrollo técnico, ejerce una mayor presión sobre los trabajadores y desencadena una disputa por el poder con el afán de apropiarse y controlar las fuerzas productivas; los trabajadores resultan oprimidos ya sea por el capitalismo o por el socialismo tecnocráticos.

Según Simone Weil, es la idea del progreso ilimitado lo que le da un carácter mitológico a las previsiones revolucionarias del marxismo: 1) La afirmación de que la técnica se desarrolla ilimitadamente es una hipótesis cuya verdad depende de la disponibilidad de energía para tal desarrollo; y aun así, nada asegura que este desarrollo conduzca a la liberación de los trabajadores. 2) Hasta ahora el desarrollo ilimitado de la técnica ha conducido a una mayor opresión de los trabajadores y a una presión más fuerte de los Estados sobre los individuos.

La opresión parece una constante en la historia de la producción humana, depende de la necesidad de producir cada vez más y de la lucha por el poder. El poder ha aumentado en la medida en que se ha desarrollado la capacidad técnica de producción material. Ha aumentado la opresión sobre los trabajadores, quienes deben producir cada vez más y más rápidamente en función de la guerra que libran los Estados para mantener el poder. Para Simone Weil la opresión parece ser el precio que una parte de la humanidad ha pagado a cambio de la libertad y las posibilidades productivas. La opresión se impone sobre el cuerpo y el espíritu del hombre. Simone Weil enfatiza que la libertad no consiste en la liberación absoluta de la necesidad material, sino en la posibilidad de alcanzar un estado de pensamiento personal y libre. Es precisamente la opresión lo más contrario al estado espiritual de libertad de pensamiento.

Simone Weil ve claramente que las condiciones de la liberación del hombre significarían un mayor equilibrio entre la necesidad natural en la forma de opresión material, y la libertad personal como capacidad de desarrollar una vida espiritual mediante el pensamiento reflexivo. 


\section{GABRIELA HERNÁNDEZ}

La circunstancia histórica en que Simone Weil escribe sus reflexiones está marcada por el triunfo de los movimientos autoritarios y nacionalistas que destruyen la esperanza en la democracia y en la paz mundial. El fascismo estaba en ascenso. En este tiempo histórico de gran desarrollo técnico y económico, Simone Weil denuncia que el trabajo no se realiza con una conciencia orgullosa, sino con un sentimiento angustiado de poseer un puesto pasajero para ganarse la existencia. El progreso técnico se ha impuesto como una realidad conflictiva, es pujante pero ha fracasado en cuanto a los fines que le adjudicaban tanto los marxistas como los capitalistas, puesto que en lugar de haber logrado el bienestar ha traído a las masas la miseria física y moral en la que se debaten. Por otro lado, el mismo desarrollo técnico parece frenarse en el ámbito productivo y sólo expandirse en el ámbito militar. La sociedad entera se movilizó por la idea de la revolución, tanto a favor como en contra, pero en las condiciones políticas que vive Simone Weil, la revolución comienza a ser más bien la ilusión de una transformación radical en favor del espíritu humano. Contra esta ilusión Simone Weil responde con su crítica a la idea de revolución y liberación total de la opresión.

Por ello, Simone Weil se concentra en una crítica al progresismo marxista. Marx explica el mecanismo de la opresión capitalista; pero lo explica tan bien que es difícil imaginar cómo podría dejar de funcionar. Aparentemente, el marxismo sólo apuesta por una transformación en el régimen de propiedad de las fuerzas productivas. Pero más bien parece que mientras haya lucha por el poder y mientras el factor decisivo de la victoria sea la producción industrial, los obreros serán explotados por un régimen o por otro. Marx suponía que la extensión planetaria de la revolución socialista haría desaparecer la lucha por el poder; pero la revolución no puede extenderse planetariamente; y aun cuando se hace en unos cuantos países, no suprime la opresión sino al contrario, la acentúa en cada uno por la necesidad de explotar a los trabajadores temiendo ser más débil que los otros. La historia de la Revolución rusa -dice Weil- constituye una ilustración dolorosa de ello. ${ }^{8}$

${ }^{8}$ Cabe recordar que Simone Weil escribe en 1934, cuando las críticas al socialismo real no son frecuentes entre los propios militantes de izquierda. 
Simone Weil observa que la fuerza que posee la burguesía para explotar y oprimir a los trabajadores radica en los fundamentos de la vida social y no puede ser abolida por ninguna transformación política o jurídica. Esta fuerza es el régimen mismo de producción técnico-industrial. En este aspecto Marx destaca la subordinación del trabajador al aparato productivo, el trastocamiento de la relación entre sujeto y objeto y la enajenación del trabajo.

Marx cree que la técnica actual, una vez liberada de las formas capitalistas de la economía, podría dar a los hombres tiempo libre para permitirles un desarrollo armónico. El desarrollo ulterior e ilimitado de la técnica debe aliviar cada vez más el peso de la necesidad material y, en consecuencia, el de la presión social sobre el trabajo necesario, hasta llegar a un estado ideal en el que la producción más abundante costaría un insignificante esfuerzo.

Simone Weil critica la inexactitud de estas ideas:

1) Marx no explica por qué las fuerzas productivas tenderían a acrecentarse y por qué cuando una institución social se opone al crecimiento de éstas, las fuerzas productivas ganarían la batalla en favor de su autodesarrollo. No es posible que los hombres transformen conscientemente el estado social para mejorar la situación económica; más imposible es que se lo propongan y que lo logren como lo habían planeado. Tal parece que existe en la teoría marxista una mano invisible providencial en el supuesto desarrollo ilimitado y progreso continuo de las fuerzas productivas. 2) Marx establece como una premisa sin fundamento histórico racional que las fuerzas productivas tienden a un desarrollo ilimitado. 3) Esta concepción desemboca en una doctrina con aspectos religiosos o míticos en la que se define al proletariado sujeto con una misión cuasi providencial.

Para Simone Weil, la gran idea de Marx es que en la sociedad, lo mismo que en la naturaleza, nada se efectúa sino por transformaciones materiales. Para proponerse una transformación social hay que conocer las condiciones materiales que determinan nuestras posibilidades de acción. En el dominio social, esas condiciones se definen por la manera en que el hombre hace frente a las necesidades materiales. Simone 


\section{GABRIELA HERNÁNDEZ}

Weil distingue en este problema dos aspectos principales: primero hay que analizar el esquema mismo de la producción para saber lo que puede esperarse de ella en el futuro inmediato en cuanto a su rendimiento; y por otro lado, qué formas de organización social y de cultura son compatibles con él. Conocer pues, los medios técnicos disponibles y los fines sociales.

El progreso técnico sólo puede medirse como mayor coordinación de esfuerzos y aun así no es predeterminable. Dado que se produce en dos direcciones interrelacionadas: a) como ahorro de energía y esfuerzo mediante ciertos instrumentos; b) como creación de nuevas posibilidades y alcances de la acción humana, lo cual implica que ese nuevo poder puede ser constructivo o destructivo. Simone Weil hace una observación más respecto a los límites del progreso técnico: "No tenemos, sin embargo, ningún medio para darnos cuenta claramente si estamos lejos o cerca del límite a partir del cual el progreso técnico debe transformarse en factor de regresión económica.” Todos estos factores hacen dudar a Simone Weil de que la técnica incrementará su desarrollo en el futuro próximo, un incremento continuo e ilimitado es inconcebible. Esto es tanto como pretender obtener una máquina de movimiento perpetuo, que produciría indefinidamente sin agotar jamás su energía.

La etapa superior del comunismo considerada por Marx como el último término de la evolución social es, en suma, una utopía absolutamente análoga a la del movimiento perpetuo.

Sin embargo, quizá pueda darse un sentido al ideal revolucionario si no en tanto perspectiva posible, al menos en tanto límite teórico de transformaciones sociales realizables. Lo que pediríamos a la revolución es la abolición de la opresión social. Pero para que esta noción al menos presente probabilidades de tener algún sentido hay que cuidarse de distinguir entre opresión y subordinación de caprichos individuales a un orden social. En tanto haya sociedad, ésta encerrará la 
vida de los individuos en límites estrechos y les impondrá sus reglas. ${ }^{9}$

Marx vio muy bien que el régimen actual de producción, o sea el de la gran industria tecnificada, reduce al obrero a no ser más que un simple instrumento en manos de los que la dirigen; es inútil esperar que el progreso técnico pueda, mediante la ejecución del esfuerzo productivo, aligerar la doble presión de la necesidad natural y de la sociedad sobre el trabajo humano. Se trata pues de saber si puede concebirse una organización de la producción tal que, incluso sin eliminar las necesidades naturales y la presión social que resulta de ellas, permita a los espíritus y a los cuerpos humanos permanecer sin ser aplastados bajo la opresión.

Y si se comprende claramente que la posibilidad de tal modo de producción no es siquiera concebible, al menos se gana el poder resignarse legítimamente a la opresión, y dejar de creerse cómplice por el hecho de que no se hace nada eficaz para impedirla. ${ }^{10}$

Simone Weil funda su teoría política en la realidad de la opresión y en el desengaño acerca de las utopías revolucionarias como solución radical. La opresión existe en donde la sociedad ha logrado cierto desarrollo económico y en donde ha sido necesaria la división del trabajo. La opresión no es una cuestión de privilegios o de injusticia, media en ella la presión de la necesidad material y la lucha por el poder. El poder implica una especie de fatalidad que pesa tan implacablemente sobre los que mandan como sobre los que obedecen. En la medida en que esclaviza a los primeros, por su intermedio, aplasta a los segundos. Conservar el poder es, para los poderosos, una necesidad vital, pues es su poder lo que los alimenta. Tienen que conservarlo a la vez

${ }^{9}$ Reflexiones sobre las causas de la libertad y de la opresión social, p. 66.

${ }^{10}$ Ibid., p. 72. 


\section{GABRIELA HERNÁNDEZ}

contra los rivales y contra sus inferiores, los que no pueden no tratar de librarse de amos peligrosos; el amo es temible al esclavo por el hecho mismo de que él lo teme y recíprocamente. El poder se reproduce en un círculo vicioso; cualquier poder debe tratar de afirmarse en el interior por medio de éxitos exteriores, pues esos éxitos le dan a su vez más fuerza interior.

Sólo se puede romper el círculo del poder mediante la supresión de la desigualdad o constituyendo un poder estable, un poder tal que establezca equilibrio entre los que mandan y los que obedecen.

Así hay, en la esencia misma del poder, una contradicción fundamental que hablando con propiedad le impide existir. Aquellos a quienes se denomina amos, obligados sin cesar a reforzar su poder bajo pena de que se lo quiten, persiguen un dominio esencialmente imposible de poseer. [...] Sería distinto si un hombre pudiera poseer en sí mismo una fuerza superior a la de muchos otros. Pero nunca es el caso, los instrumentos del poder, armas, oro, máquinas, secretos mágicos o técnicos, existen siempre fuera del que los dispone y pueden ser tomados por otro. Así todo poder es inestable. ${ }^{11}$

En general, entre los seres humanos las relaciones de dominio y sumisión, por no ser nunca plenamente aceptables, constituyen siempre un desequilibrio sin remedio que se agrava progresivamente. En las relaciones sociales, en la medida en que los métodos de trabajo y de la guerra excluyen la igualdad, parecen hacer pesar la locura sobre los hombres como una fatalidad exterior. Pues por el hecho mismo de que el poder no posee completamente su objeto sino que es una búsqueda interminable, no existen límites en los esfuerzos que exige.

De este modo la carrera por el poder esclaviza a todo el mundo, a los poderosos como a los débiles. Marx lo vio muy bien en lo que respecta al régimen capitalista [...] donde el consumo

${ }^{11}$ Ibid., p. 84. 
aparece como un ‘mal necesario’ que hay que reducir al mínimo, un simple medio para mantener en vida a los que se consagran sea como jefes, sea como obreros, al fin supremo. Este fin no es otro que la fabricación de la maquinaria, es decir de los medios de producción. [...] El único carácter propio de este régimen es que los instrumentos de la producción industrial son al mismo tiempo las principales armas en la carrera del poder. Pero siempre los procedimientos de la carrera por el poder someten a los hombres, sean cuales fueren, por el mismo vértigo y se imponen como fines absolutos. [...] El verdadero tema de $L a$ Ilíada es el poder de la guerra sobre los guerreros, y a través de ellos, sobre todos los seres humanos. Nadie sabe por qué cada uno se sacrifica y sacrifica a los suyos en una guerra asesina y sin objeto... ${ }^{12}$

Así la lucha por el poder desencadena un proceso de sustitución de fines por medios. Tan pronto aparece la guerra, la riqueza, la técnica, la producción, como fines en sí mismos a los que se les ofrenda la vida de los seres humanos. El poder es por definición sólo un medio; poseer un poder es más bien poseer ciertos medios de acción que rebasen la fuerza individual o colectiva. Pero la persecución del poder, por el mismo hecho de que se hace esencialmente impotente para lograr su fin, excluye toda consideración de los fines y llega por una inversión inevitable como compensación de fuerzas, a ocupar el lugar de todos lo fines, subyugando a todos por igual.

La historia humana no es más que la historia de la servidumbre que hace de los hombres, tanto opresores como oprimidos, el simple juguete de instrumentos de dominación fabricados por ellos mismos, y rebaja así a la humanidad viviente a ser cosa de cosas inertes. Por eso ya no son los hombres, sino las cosas las que dan a esta carrera vertiginosa por el poder sus

${ }^{12}$ Ibid., p. 85. 
GABRIELA HERNÁNDEZ

límites y sus leyes. Los deseos de los hombres son impotentes para regularlos. ${ }^{13}$

Nuestra autora advierte que para suprimir la opresión habría que eliminar sus fuentes, abolir todos los monopolios, los armamentos, los secretos técnicos que dan poder sobre la naturaleza, el dinero, etcétera. La opresión está en la naturaleza misma de la producción y la reproducción de la vida social. Es una ilusión suponer que la opresión dejaría de ser necesaria mediante el desarrollo de las fuerzas productivas. La elevación del rendimiento del trabajo será impotente para aliviar el peso de la opresión mientras la estructura social implique el trastocamiento entre fines y medios; mientras la organización del trabajo y la guerra den a algunos un poder sobre los demás. Simone Weil considera que la concepción marxista según la cual la existencia social está determinada por las relaciones entre el hombre y la naturaleza (la producción), sigue siendo la única base para todo estudio histórico; pero esas relaciones deben comprenderse en función del problema del poder, en el que los medios de subsistencia constituyen sólo un dato. El poder depende de las condiciones materiales de la vida pero no deja nunca de transformar y organizar esas mismas condiciones.

Cualquier poder se apoya en instrumentos que tienen un alcance determinado; así no se gobierna de la misma manera con caballería y espadas que por medio de aviones y tanques. En segundo lugar, el poder choca siempre contra los límites de la facultad de control de los que lo detentan. El poder colectivo o disuelto en la colaboración constituye en apariencia un medio eficaz de su control; pero en realidad genera una serie de rivalidades internas y de complicaciones infinitas. El poder colectivo es una ficción, éste no se comparte, sólo se arrebata. Todo poder se esfuerza por mejorar en su propio dominio la producción y control; pero también se esfuerza por destruir a sus rivales. Todo poder, por el hecho mismo de ejercerse, extiende hasta el límite de lo posible las relaciones sociales sobre las cuales reposa. Así, el poder

${ }^{13}$ Ibid., p. 86. 
militar multiplica las guerras y el capital comercial multiplica el mercado mundial.

No obstante todo poder determinado tiene su límite, el cual alcanzaría si pudiera extender al máximo sus medios de control, sus recursos y su capacidad de autorregulación; al extender indefinidamente el alcance de sus propios instrumentos tendería a abolir la esencial correlación y diferencia entre el amo y el esclavo. Esto no quiere decir que sea absolutamente imposible la reproducción ilimitada de un poder, pero al menos hay que concebir que todo poder tiene un límite después del cual choca contra sí mismo. El poder no se disuelve por esta contradicción interna, pues no le es fácil detenerse, siempre está obligado a ir cada vez más lejos rebasando los límites dentro de los cuales puede ejercerse con efectividad. Tal es la contradicción interna que todo régimen opresor lleva en sí, constituida por la oposición entre sus bases materiales y el carácter necesariamente ilimitado de la carrera entre los hombres. Esta lucha desencadena los episodios más trágicos de la historia en los que el poder se extiende más allá de lo que puede controlar, engendrando parasitismo, corrupción, derroche y desorden social. Tratando de mandar más allá de lo que puede obligar, provoca reacciones que no puede prever ni controlar; queriendo extender la explotación de los oprimidos más allá de lo que permiten los recursos objetivos, agota esos mismos recursos. Esta contradicción en la que el principio de explotación en vez de ser más productivo se vuelve cada vez más costoso parece una constante, a menos que supongamos la posibilidad de disponer de recursos inagotables. La desmesura, la hybris del poder, es al mismo tiempo su única vía de permanencia y de agotamiento.

En qué consiste el lazo que hasta ahora parece unir la opresión social y el progreso en las relaciones del hombre con la naturaleza. [...] Pareciera que el hombre no puede aliviar el yugo de las necesidades materiales sin aumentar el de la opresión social, como por el juego de un misterioso equilibrio. ${ }^{14}$

${ }^{14}$ Ibid., p. 97. 


\section{GABRIELA HERNÁNDEZ}

Aunque la humanidad parece haber llegado a disponer de las fuerzas de la naturaleza mediante el poder técnico, esta victoria no pertenece a los hombres tomados uno a uno. Los miembros de las sociedades, opresores y oprimidos, están igualmente sometidos a las implacables exigencias de la lucha por el poder. Así, a despecho del progreso, el hombre no ha salido de la condición servil en la que se encontraba ante las fuerzas ciegas del universo; simplemente el poder que lo mantiene de rodillas ha sido transferido de la materia inerte a la sociedad de la gran industria.

Hay que [...] buscar por qué el hombre ha debido pagar a ese precio su dominio sobre la naturaleza, concebir en qué puede consistir la situación menos desdichada para él, es decir aquella en que estaría menos avasallado por la doble dominación de la naturaleza y la sociedad, en fin, ver qué caminos pueden llevar a tal situación y qué instrumentos la civilización actual podría proporcionar a los hombres de hoy si aspirasen a transformar su vida en ese sentido. ${ }^{15}$

28 Así, el hombre sólo escapa en cierta medida a los caprichos de la necesidad natural sometiéndose a la cadena interminable de la lucha por el poder. Esto nunca es tan verdadero como cuando el hombre alcanza una técnica bastante avanzada para dominar a las fuerzas de la naturaleza. De esta manera la humanidad se subordina bajo una nueva forma que le da el progreso técnico, a las fuerzas de la naturaleza, como jamás lo fue -dice Simone Weil- en los tiempos primitivos. "Hemos tenido, tenemos y tendremos, esta amarga experiencia. [...] Parecería que el hombre nace esclavo y que la servidumbre es su condición propia.”

El diagnóstico de Simone Weil acerca de nuestro tiempo no es menos agudo:

${ }^{15}$ Ibid., p. 99. 
Vivimos en un mundo donde nada es a la medida del hombre; hay una desproporción monstruosa entre el cuerpo del hombre, el espíritu y las cosas que constituyen actualmente los elementos de la vida humana; todo está desequilibrado. ${ }^{16}$

El hombre se encuentra ante el mundo técnico en una situación peligrosa. No sólo porque podría estallar una guerra mundial o porque podrían explotar plantas generadoras de energía atómica por todas partes; aun la aniquilación completa de la Tierra y por tanto de la humanidad, no son la amenaza más inmediata o más evidente; insistimos, el verdadero peligro no está en la aniquilación, sino en la posibilidad en donde todavía opera la libertad humana y en donde, por tanto, debemos decidir una posición vital en el mundo. Veamos:

[...] la revolución de la técnica que se avecina en la era atómica pudiera fascinar al hombre, hechizarlo, deslumbrarlo y cegarlo de tal modo, que un día el pensar calculador pudiera llegar a ser el único válido y practicado. ${ }^{17}$

Entonces el verdadero peligro consiste en que el hombre extirpe en sí mismo lo más propio: su pensamiento reflexivo y meditativo, su autoconciencia, su auténtico modo de habitación en la Tierra. Hay que salvaguardar esta facultad esencial del hombre, hay que mantener despierto el pensamiento reflexivo. Antes que una mutación irreversible en la anatomía o en la constitución genética humana, el imperio del mundo técnico implica un peligro más esencial y más oculto, el cual apenas hemos empezado a identificar: el peligro ya latente de que nuestras posibilidades vitales de relación con el ser se reduzcan; que nuestra constitución ontológica se transmute y pierda lo más esencial y lo que nos ha permitido desarrollarnos como seres sobrenaturales en medio de la naturaleza. La naturaleza humana no es inmutable y es,

${ }^{16}$ Ibid., p. 129.

${ }^{17}$ Ibid., p. 29. 


\section{GABRIELA HERNÁNDEZ}

por lo demás, histórica, es decir, creada por nosotros mismos; dentro de estas posibilidades de ser hombre, bien puede ocurrir que elijamos, sin ser totalmente conscientes de ello, y por no ser una ‘elección’ voluntaria, elijamos pues, insertarnos sin reflexión ni conciencia en un mundo que, aunque obra nuestra, adquiere autonomía y se autorregula, al cual servimos ya como medios y no controlamos ni dirigimos según nuestros fines vitales, porque ya no sabemos cuáles son éstos. Sin pensamiento, sin reflexión y sin arraigo no es posible, en verdad, definir la finalidad de una vida que no puede subsistir sin programa, a menos que se halle perdida en un mundo ajeno sólidamente compuesto de una infinidad de medios técnicos que se convierten en fines absolutos de la existencia. 